\title{
TOLL LIKE RECEPTOR-4 GENE ASPARTATE 299 GLYCINE POLYMORPHISM IN SUDANESE PATIENTS WITH MYCETOMA
}

\author{
Mazin Babekir Musa ${ }^{* 1} \boldsymbol{\square}$ (D), Ismail Abdalsamad 2, Najwa. A.Mhmoud 3, Haghamad \\ Allzain ${ }^{4}$, Sahar M Bakhiet 5 \\ ${ }^{1}$ Department of Microbiology, Faculty of Medical Laboratory Sciences, Shendi University, Sudan \\ 2 Faculty of Pharmacy, University of Khartoum, Sudan \\ ${ }^{3}$ Department of Microbiology, Faculty of Medical Laboratory Sciences, University of Khartoum, \\ Sudan \\ ${ }^{4}$ Department of Biochemistry, Faculty of Medicine, Shendi University, Sudan \\ ${ }^{5}$ Institute of Endemic Diseases, University of Khartoum, Sudan
}

DOI: https://doi.org/10.29121/granthaalayah.v9.i2.2021.3492

Article Type: Research Article

Article Citation: Mazin Babekir Musa, Ismail Abdalsamad, Najwa. A.Mhmoud, Haghamad Allzain, and Sahar M Bakhiet. (2021). TOLL LIKE RECEPTOR-4 GENE ASPARTATE 299 GLYCINE POLYMORPHISM IN SUDANESE PATIENTS WITH MYCETOMA. International Journal of Research -GRANTHAALAYAH, 9(2), 187-192.

https://doi.org/10.29121/granthaa layah.v9.i2.2021.3492

Received Date: 28 January 2021

Accepted Date: 28 February 2021

Keywords:

Mycetoma

DNA

TLR-4

PCR

RFLP

Asp

GLY

\section{ABBREVIATIONS}

Asp, Aspartate; Gly , glycine; TLR-4, toll like receptor-4; DNA, deoxyribonucleic acid; PCR, polymerase chain reaction; RFLP, restriction fragment length polymorphism ; SNP, single nucleotide polymorphism; rs, restriction site.

\section{ABSTRACT}

Background: Mycetoma is a neglected tropical disease characterized by deformity and disabilities with various medical, health, and socioeconomic impacts on the affected communities. The etiological factors associated with Mycetoma have not been fully understood, however genetic predisposition and inflammation are considered as Mycetoma risk factors. Toll like receptors (TLRs) are key players in the innate immune response and play a great role in immunesurveillance and inflammation. This study was conducted to investigate the potential role of TLR4 polymorphism (Asp299Gly) as a risk factor for development of Mycetoma.

Objectives: To determine the presence of TLR4 polymorphism (Asp299Gly) in Sudanese Mycetoma patients as well as measuring allele frequency and genotype distribution of this mutation among Mycetoma patients and healthy controls.

Material and Methods: The current study included ninety five (95) subjects, of whom fifty (50) were confirmed Mycetoma patients and forty five (45) were healthy volunteer controls. It was conducted at the Institute of Endemic Diseases and Mycetoma Research Centre; University of Khartoum in the period, from June 2015 to June 2016. DNA was isolated from blood samples of study subjects and TLR-4 gene polymorphism Asp299Gly was determined using PCR-RFLP with Nco1 restriction enzyme. Genotypes distribution and allele frequencies in the two groups were measured.

Results and conclusion: There was insignificant difference in allele distribution of TLR4 (Asp299Gly) A/G (rs 4986790) in Mycetoma patients compared with the healthy controls. TLR4 (Asp299Gly) polymorphism (rs 4986790) was found in twenty(20) out of fifty (50) Sudanese patients with Mycetoma , that is forty percent (40\%) and twenty seven (27) out of forty five (45) healthy control, that is sixty percent $(60 \%)$.

Further studies are needed in a large and ethnically diverse population to determine the impact of the TLR-4 polymorphism in the susceptibility to Mycetoma. 
Toll like receptor-4 gene aspartate 299 glycine polymorphism in Sudanese patients with Mycetoma

\section{INTRODUCTION}

Mycetoma is a unique neglected tropical disease. It is a morbid subcutaneous chronic progressive inflammatory condition caused by certain fungi (eumycetoma) or bacteria (actinomycetoma) [1], [2], [3]. The organisms inhabit the soil and can enter the subcutaneous tissue via traumatic inoculation. Mycetoma commonly affects adults aged between 20 to 40 years, predominantly males. Both forms of Mycetoma present as a progressive, subcutaneous swelling, although Actinomycetoma has a more rapid course. Multiple nodules develop which may produce pus that drains through sinuses, discharging grains during the active phase of the disease [4]. There are more than seven thousands (7000) patients who received treatments at the Mycetoma Research Centre-University of Khartoum [5].

The innate immune system detects invading pathogens through pattern-recognition receptors that represents the first line of host defense. It comprises a family of receptors termed Toll-like receptors (TLRs).These proteins recognize and bind to microbial pathogens, thereby inducing rapid innate immune response to microbial invaders [6]. In previous studies it was shown that TLRs have been implicated in the recognition and triggering of immunity during fungal infections in mammals [7], [8]. Toll-like 4 (TLR4) is an essential component of the innate immune response to various microorganisms. Genetic polymorphisms in TLR4 are often associated with susceptibility to fungal diseases. Additionally it was reported that TLR4 mediate cytokine release in response to different developmental stages of $A$. fumigatus [9], [10]. Furthermore Leukocyte activation induced by Candida albicans also involves TLR2 and TLR4 triggering [11], [12].

Direct sequencing of TLR4 gene led to the identification of single-nucleotide polymorphism (SNP), an A-G substitution at nucleotide position +896 resulting in an amino acid replacement .Asp299Gly SNP in the third exon of TLR-4 gene has a positive correlation with susceptibility to aspergillosis, gram-negative sepsis, atherosclerosis, asthma, malaria, and Helicobacter pylori-induced gastric cancer [13], [14], [15].

The aim of this study was to assess the distribution of TLR4 (Asp299Gly) polymorphism in Sudanese patients with Mycetoma.

\section{MATERIAL AND METHODS}

Study design: This study was a hospital based case control (pilot study) conducted at the Institute of Endemic Diseases and Mycetoma Research Centre; University of Khartoum. The The study included ninety five (95) subjects of whom, fifty (50) confirmed Mycetoma patients and (45) healthy controls. In the period from June 2015 to June 2016.

Study subjects: Mycetoma patients were diagnosed using careful interview, meticulous clinical examinations and specific investigations included culture, fine needle aspiration (FNA) for cytology and histopathological examination of surgical biopsies. In the latter, different staining techniques were used. The commonest is haematoxylin and eosin (H\&E) stain which is adequate for identifying most of the grains types. Grains obtained from surgical biopsies were inoculated in different media. Eumycetes grains were cultured in blood agar and Sabouraud dextrose agar and were incubated at $37^{\circ} \mathrm{C}$ for six - eight weeks. The controls group included healthy Sudanese controls of matched age, sex and ethnic background.

Isolation of genomic DNA: DNA was extracted from peripheral blood using guanidine hydrochloride method. Proteinase K, $300 \mu \mathrm{l}$ of 7.5M Ammonium Acetate, and $1 \mathrm{ml}$ of $6 \mathrm{M}$ Guanidine Chloride were added and incubated at $37^{\circ} \mathrm{C}$ overnight. Next day samples were cooled to room temperature and $1 \mathrm{ml}$ pre-chilled Chloroform was added and centrifuged at $3000 \mathrm{rpm}$ for 20 minutes. Three layers were separated. The supernatant was collected to a new tube. $10 \mathrm{ml}$ of pre-chilled absolute Ethanol were added and mixed gently. Samples was placed into $-20^{\circ} \mathrm{c}$ freezer for 24 hours. Next day after vortexing and centrifuging for 15 minutes at $3000 \mathrm{rpm}$ the supernatant was discarded. Then washing by $4 \mathrm{ml} 70 \%$ ethanol was performed. After drying from alcohol, DNA pellet was resuspended in $200 \mu \mathrm{l}$ of deionized water and was placed into $4^{\circ} \mathrm{C}$ for one day to insure total dissolving of the pellet.

\section{GENOTYPING OF TLR 4 ASP299GLY POLYMORPHISM}

Polymerase chain reaction (PCR) amplification of TLR-4 gene for the detection of Asp299Gly SNP was done using gene-specific primers sequence: 


\section{F-GATTAGCATACTTAGACTACTACCTCCATG \\ R-GATCAACTTCTGAAAAAGCATCCCAC}

Amplification reaction was carried out in final volume of $20 \mu \mathrm{l}$ using Maxime PCR PreMix Kit (i-Tag) Cat. No25025 (for $20 \mu \mathrm{l}$ rxn. 96 tubes) containing i - Tag DNA Polymerase (5U / $\mu$ l) dNTPs $2.5 \mathrm{mM}$ each, Reaction Buffer (10x) 1x. For each20 $\mu \mathrm{l}$ reaction, $2 \mu \mathrm{l}$ of DNA were added to the mixture (50 ng / $\mu \mathrm{l}$ of DNA) primer $(10 \mathrm{pmol} / \mu \mathrm{l})$, then completed to $20 \mu \mathrm{l}$ with double distilled water. The amplification was done for 35 cycles: $30 \mathrm{~s}$ denaturation at $94^{\circ} \mathrm{C}$, 30s annealing at $55^{\circ} \mathrm{C}, 30 \mathrm{~s}$ extension at $72^{\circ} \mathrm{C}$, with $10 \mathrm{~min}$ final extension at $72^{\circ} \mathrm{C}$. The amplified product was visualized under UV transilluminator on $2 \%$ agarose gel containing ethidium bromide $(0.5 \mu \mathrm{g} / \mathrm{ml})$.

The resulting PCR product was digested for 5 hours with Nco1restriction enzyme .The digest reaction was set up using $4 \mu \mathrm{l}$ PCR product, $1 \mu \mathrm{l} 10 \mathrm{x}$ enzyme buffer , $0.5 \mu \mathrm{l}$ Nco 1 enzyme and $4.5 \mu \mathrm{l}$ water then visualized on 3\% agarose gel stained with ethidium bromide.

\section{Ethical consideration}

This study was approved by the ethical committee of the Institute of Endemic Diseases - University of Khartoum -Sudan. Written informed consent was obtained from patients and controls. Names and personal data were completely secured and transferred to codes to keep the privacy of patients' identities.

\section{STATISTICAL ANALYSIS}

All statistical calculations were performed using SPSS for windows, version 20.

The data were cleaned and checked for consistency before entering it for analysis.

Genotype distribution and allele frequencies in different groups were compared by chi-square test. Results were considered significant, at level of $(\mathrm{P} \leq 0.05)$.

\section{RESULT}

This study included ninety five (95) participants, fifty (50) Patients and forty five (45) controls that were assessed for the presence of TLR4 Asp299Gly. The demographic characteristics of the patients at study entry are Myctoma patients in study population, of whom thirty eight (38) males and twelve (12) females, with male to female ratio $3.2: 1$ and a mean age of $34.64 \pm 15$ years.

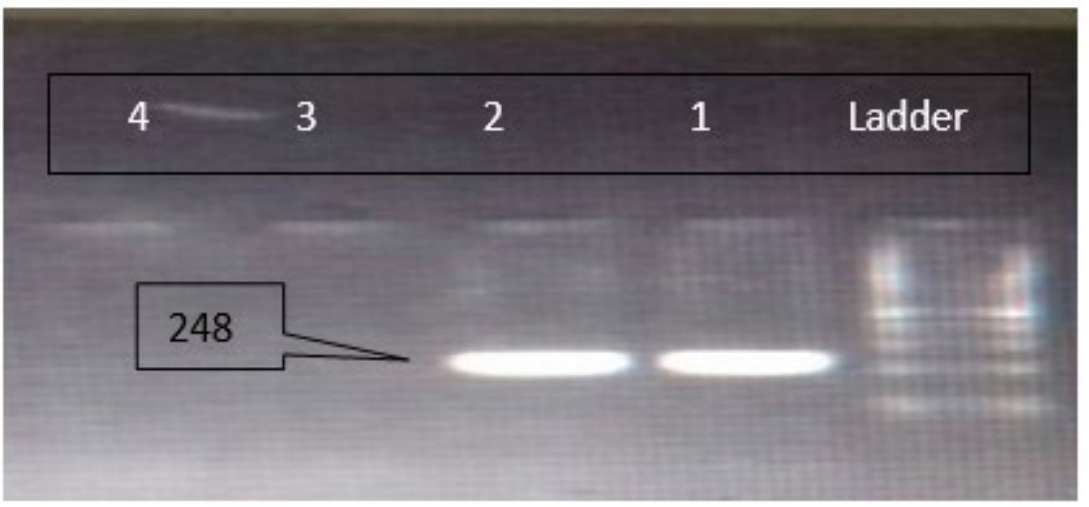

Figure 1: PCR gel electrophoresis on 2.0\% agarose gel .1 and 2 PCR products of 248 bp DNA fragments, 3 and 4 negative controls (no DNA)

For the purpose of polymorphism genotyping PCR-RFLP was used using Nco1 restriction enzyme. This resulted in: homozygous wild type allele with single band 248 bp lengths, mutant type allele with twin bands 222 and 26 bp length. On comparing the frequency of genotypes with respect to Asp299Gly, it was found that Wild type (allele A): Mutant type (allele G): had no association [OR $0.44,95 \%$ CI , $(0.195-1.011)$ P $=0.052$ ] with susceptibility to Mycetoma. 
Toll like receptor-4 gene aspartate 299 glycine polymorphism in Sudanese patients with Mycetoma

Table 1: The summary of RFLP result:

\begin{tabular}{|c|c|c|c|}
\hline TLR4 polymorphism & Restriction enzyme & Restriction temperature (Co & Length of fragments \\
\hline Asp299Gly & Nco1 & 55 & Wild type (allele A): $248 \mathrm{bp}$ \\
\hline & & & Mutant type(allele G): $222+26 \mathrm{bp}$ \\
\hline
\end{tabular}

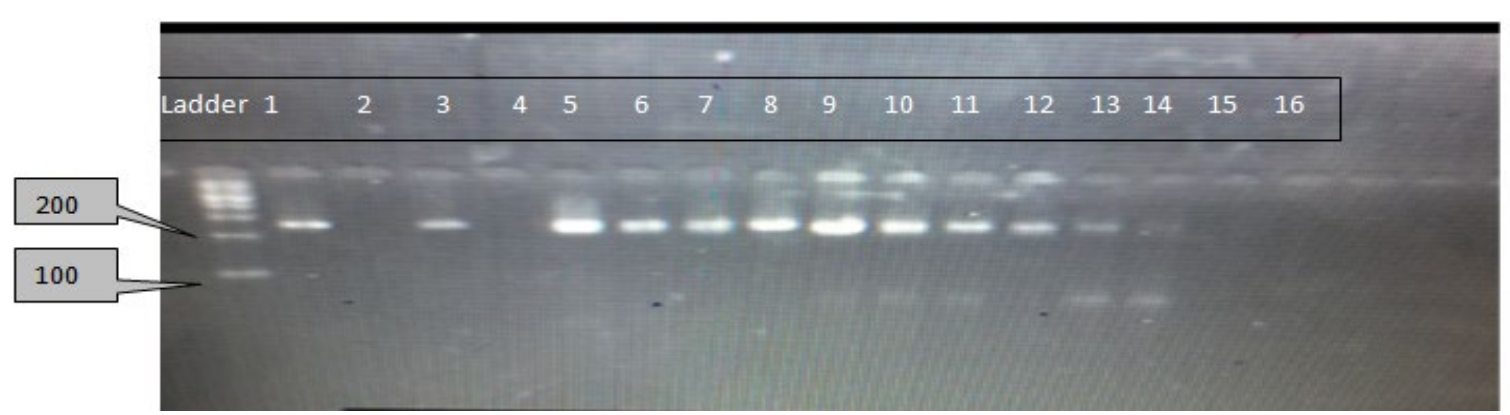

Figure 2: (3\%) Agarose gel showing restriction digestion of PCR products. 1,3,5,6,7,8 and 12 are wild-type $; 9,10,11,13$,and 14 are heterozygous ; 15 and 16 are negative controls .

Table 2: Allele frequency of (Asp299Gly) in Mycetoma patient compared to the controls

\begin{tabular}{|c|c|c|c|c|}
\hline Nucleotide change & Case frequency & Control frequency & OR & P \\
\hline A & 0.60 & 0.40 & 0.44 & 0.052 \\
\hline G & & & $(0.195-1.011)$ & \\
\hline & 0.40 & 0.60 & 2.25 & 0.052 \\
\hline & & & $(0.989-5.119)$ & \\
\hline
\end{tabular}

\section{DISCUSSION}

Mycetoma is endemic in many countries in the tropics and subtropics although most cases are reported from Sudan, Mexico, and India. Of the different immunologic molecules which are thought to be implicated in the pathogenesis of Mycetoma are toll like receptors. The current study was conducted to investigate the effect of TLR4 mutation (rs 4986790) in vulnerability to Mycetoma among Sudanese population.

This study to the of knowledge exist, is the first study to address association of this mutation with the disease in Sudan.

The TLR4 (rs 4986790) mutation involves replacement of aspartate by glycine at amino acid residue 299, at the third exon of the conserved regions of TLR4. This takes place when there is an A to G substitution at nucleotide +896 from the start codon of the TLR4 gene. These single nucleotide polymorphisms (SNPs) in the extracellular domain of TLR4 may alter the ligand binding capacity [16] and disturbs the pro- and anti-inflammatory cytokines, hence modulating the risk of chronic inflammation and development of disease.

The association of different SNPs and susceptibility to Mycetoma has been reported previously. In one study by Wendy et al , significant differences in allele distribution for IL-8 (CXCL8), its receptor CXCR2, thrombospondin-4 (TSP-4), NO synthase 2 (NOS2), and complement receptor 1 (CR1) were reported in Mycetoma patients [17]. Further In another study by Najwa et al, carried out at the Mycetoma Research Center in University of Khartoum , in Sudan concluded that a significant association between susceptibility to Mycetoma and interleukin-10 cytokine and CC chemokine ligand 5 polymorphisms [18].

In the current study the proportions of individuals carrying TLR4 Asp299Gly were different for cases and controls (40\% and 60\%) respectively. The majority of Mycetoma patients in this study were males, with male to female Ratio (3.2:1) , this agrees with the results obtained by Lopez-Martinez et al [19], Castro et al [20] and Fahal [4]: who found that in Mycetoma infected individual male to female ratios were in the range of (1.6-6.6:1).

Our findings demonstrated no association of this SNP with Mycetoma as most of the patients had AG genotype $(40 \%)$ as compared to controls (60\%). However, this result is contrary to Lorenz, et al [15], Ahmed, et al [21] and Koldehoff, et al [22], who found a significant association between the TLR4 (Asp299Gly) polymorphism and susceptibility to aspergillosis, gram-negative sepsis, atherosclerosis, asthma, malaria, and Helicobacter pyloriinduced gastric cancer. This indifference could be explained by the small sample size in our study. 
Mazin Babekir Musa, Ismail Abdalsamad, Najwa. A.Mhmoud, Haghamad Allzain, and Sahar M Bakhiet

Most of the control study subjects held the mutant type allele with higher frequency being (60\%) as compared with only (40\%) of cases, which may contribute in the protection against the disease. This agreed with Sellers et al [23], Da Silva Santos et al [24] and Hawn et al [25], who stated that TLR4(Asp299Gly) polymorphism had conferred a decreased risk to periodontitis caused by P. gingivalis, malaria and Legionnaires' disease respectively.

\section{CONCLUSION AND RECOMMENDATIONS}

TLR4 (Asp299Gly) polymorphism (rs 4986790) was found in twenty(20) out of fifty (50) Sudanese patients with Mycetoma, that is forty percent (40\%) and twenty seven (27) out of forty five (45) healthy control, that is sixty percent (60\%).It is recommended that More subjects are to be included in the study to empower the study furthermore.

\section{AUTHOR'S CONTRIBUTIONS}

1) Mazin Babekir Musa : the principal investigator, conceived the idea, conducted laboratory analysis , collected the data, interpreted the data generated and wrote the draft of the manuscript.

2) Ismail Abdalsamad Abdalla: co- researcher, contributed in data collection, laboratory analysis and interpreted the data generated and wrote the draft of the manuscript.

3) Najwa. A. Mhmoud: contributed in the laboratory analysis.

4) Dr. Haghamad Allzain : provided critical suggestions and comments and edited the manuscript.

5) Sahar M Bakhiet: the supervisor of the research

\section{SOURCES OF FUNDING}

This research received no specific grant from any funding agency in the public, commercial, or not-for-profit sectors.

\section{CONFLICT OF INTEREST}

The author have declared that no competing interests exist.

\section{ACKNOWLEDGMENT}

None.

\section{REFERENCES}

[1] Fahal AH. (2004) Mycetoma thorn on the flesh. Trans R Soc Trop Med Hyg. 98(1) 2.

[2] Fahal AH, Hassan MA. (1992) Mycetoma. Br J Surg. 79(11): 1138-1141.

[3] Bonifaz A, Tirado-Sánchez A, Calderón L, Saúl A, Araiza J, et al. (2014) Mycetoma: experience of 482 cases in a single center in Mexico. PLoS Negl Trop Dis. 21; 8(8):e3102 doi:

[4] A.H. Fahal, 15May 2003; accepted 4 June 2003: Mycetoma: a thorn in the flesh.

[5] Eduard E Zijlstra, Wendy W J van de Sande, Oliverio Welsh, El Sheikh Mahgoub, Michael Goodfellow, Ahmed H Faha l(Dis 2016) Mycetoma: a unique neglected tropical disease.

[6] Medzhitov R. Toll-like receptors and innate immunity. Nat RevImmunol 2001; 1: 135-145.

[7] Netea M. G., Van der Graaf C., Van der Meer J. W., Kullberg B. J. (2004) Eur. J. Clin. Microbiol. Infect. Dis. 23, 672-676

[8] Levitz S. M. (2010) PLoS Pathog. 6, e1000758.

[9] Mambula S. S., Sau K., Henneke P., Golenbock D. T., Levitz S. M. (2002) J. Biol. Chem. 277, 39320-39326

[10] Netea M. G., Warris A., Van der Meer J. W., Fenton M. J., Verver-Janssen T. J., Jacobs L. E., Andresen T., Verweij P. E., Kullberg B. J. (2003) J. Infect. Dis. 188, 320-326 
Toll like receptor-4 gene aspartate 299 glycine polymorphism in Sudanese patients with Mycetoma

[11] Netea M. G., Gow N. A., Munro C. A., Bates S., Collins C., Ferwerda G., Hobson R. P., Bertram G., Hughes H. B., Jansen T., Jacobs L., Buurman E. T., Gijzen K., Williams D. L., Torensma R., McKinnon A., MacCallum D. M., Odds F. C., Van der Meer J. W., Brown A. J., Kullberg B. J. (2006) J. Clin. Invest. 116, 1642-1650

[12] Netea M. G., Van Der Graaf C. A., Vonk A. G., Verschueren I., Van Der Meer J. W., Kullberg B. J. (2002) J. Infect. Dis. 185, 1483-1489

[13] Rodrigo T. FigueiredoPatrícia L. FernandezFabianno F. Dutra, Yissett González, Lívia Cristina LopesVera Carolina B. Bittencourt, Guilherme L. Sassaki, Eliana Barreto-Bergter, and Marcelo T. Bozza (2010 Oct 19) TLR4 Recognizes Pseudallescheria boydii Conidia and Purified Rhamnomannans

[14] Arbour NC, Lorenz E, Schutte BC, Zabner J, Kline JN, Jones M, et al. TLR4 mutations are associated with endotoxin hyporesponsiveness in humans. Nat Genet 2000;25:187-91.

[15] Lorenz E, Mira JP, Cornish KL, Arbour NC, Schwartz DA. A novel polymorphism in the toll like receptor 2 gene and its potential association with staphylococcal infection. Infect Immun 2000;68:6398-401

[16] N. C. Arbour, E. Lorenz, B. C. Schutte et al., "TLR4 mutations are associated with endotoxin hyporesponsiveness in humans," Nature Genetics, vol. 25, no. 2, pp. 187-191, 2000. View at Publisher • View at Google Scholar

[17] Wendy W. J. van de Sande, Ahmed Fahal, Henri Verbrugh and Alex van Belkum Polymorphisms in Genes Involved in Innate Immunity Predispose Toward Mycetoma Susceptibility September 1, 2007 vol. 179 no. 5 3065-3074

[18] Najwa A. Mhmoud, Ahmed H. Fahal and Wendy W. J. van de Sande The association between the interleukin10 cytokine and CC chemokine ligand 5 polymorphisms and mycetoma granuloma formation October 28, 2012

[19] Lopez-Martinez R, Mendez-Tovar LJ, Bonifaz A, et al. Update on the epidemiology of mycetoma in Mexico. A review of 3933 cases.Gac Med Mex 2013; 149: 586-92 (in Spanish).

[20] Castro LG, Piquero-Casals J. Clinical and mycologic fi ndings and therapeutic outcome of 27 mycetoma patients from Sao Paulo,Brazil. Int J Dermatol 2008; 47: 160-63.

[21] Ahmed AO, van Leeuwen W, Fahal A, van de Sande W, Verbrugh H, et al. (2004) Mycetoma caused by Madurella mycetomatis: a neglected infectious burden. Lancet Infect Dis. 4(9):566-74.

[22] M. Koldehoff, D.W. Beelen, A.H. Elmaagacli(3 February 2013) Increased susceptibility for aspergillosis and post-transplant immune deficiency in patients with gene variants of TLR4 after stem cell transplantation

[23] Sellers RM, Payne JB, Yu F, LeVan TD, Walker C, Mikuls TR TLR4 Asp299Gly polymorphism may be protective against chronic periodontitis.2016 Apr;51(2):203-11

[24] da Silva Santos S, Clark TG, Campino S, Suarez-Mutis MC, Rockett KA, Kwiatkowski DP, Fernandes 0. Investigation of host candidate malaria-associated risk/protective SNPs in a Brazilian Amazonian population. 2012;7(5):e36692

[25] Hawn TR, Verbon A, Janer M, Zhao LP, Beutler B, Aderem A. Toll-like receptor 4 polymorphisms are associated with resistance to Legionnaires' disease. 2005 Feb 15;102(7) 